\title{
The Reading Cure
}

\section{Jen Tomkins}

\section{The Reading Cure event}

The Reading Cure, hosted by The Reader Organisation and The Lancet, held on 14 January 2009 at the Wellcome Collection, London, UK brought together medical professionals, academics, librarians, researchers, journalists, policymakers, and representatives from funding bodies and publishers to open up a discussion about the relation between reading literature and health.

"It's very difficult for people to read if they really aren't well and one thing I never encountered was a group where people read together - I think that's a fantastic idea - I would have loved to have had that and it would have got over the hurdle of facing a book, facing words, facing reading alone." [Clare Allan, author of Poppy Shakespeare]

The event was chaired by Blake Morrison (author, journalist and Chair of The Reader Organisation's Board of Trustees) and the panellists were Dr Jane Davis (Founder and Director, The Reader Organisation), Clare Allan (author and journalist), Dr Richard Horton (Editor-inChief, The Lancet) and Dr David Fearnley (Consultant Forensic Psychiatrist and Medical Director, Mersey Care NHS Trust). In an enthusiastic and engaging conversation, the panel and audience members discussed what to read, the difference between reading when you're unwell and when you're in full health, and the importance of researching and evaluating the benefits reading can have on human well-being.

The Reading Cure's keynote speech was delivered by Dr Jane Davis. She told the story of a retired general practitioner, who had tended Liverpool's sick during World War 2. In poor health, but with her strong spirit intact, this lady had begun attending Jane's literature course in the School of Continuing Education at the University of Liverpool where, in a group, she read Shakespeare, Milton and Dante.

"She was dying and we couldn't cure her," Jane explained, "but we did give her an extra piece of armour against the pain”.

\section{Get Into Reading}

Inspired by what she had seen, Jane founded The Reader Organisation, and in 2001 developed 'Get Into Reading' a pioneering social outreach project that uses great literature to make a real difference to the health and wellbeing of the local community. There are now more than 80 Get Into Reading groups meeting each week across Merseyside in community centres, libraries, day centres, doctors' surgeries, drug rehabilitation centres and care homes. What makes these groups unique is that the stories and poems are read aloud, in real time, by a trained group facilitator. This provides immediate engagement with the text, which is enriched by the spontaneous sharing of life stories and experiences as confidence builds over time.

\section{J Fam Plann Reprod Health Care 2009; 35(2): 73-74}

The Reader Organisation, Liverpool, UK Jen Tomkins, BA, Communications Officer

Correspondence to: Ms Jen Tomkins, The Reader Organisation, 19 Abercromby Square, Liverpool L69 7ZG, UK.

E-mail: jentomkins@thereader.org.uk

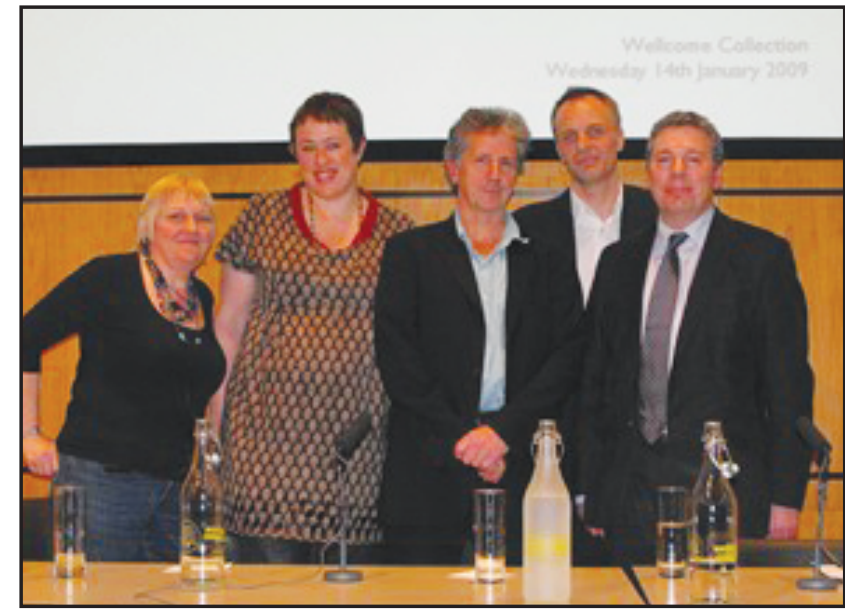

Figure 1 Panel at The Reading Cure event, from left to right: Dr Jane Davis, Clare Allan, Blake Morrison, Dr Richard Horton and Dr Dave Fearnley (photograph courtesy of Liz Thompson)

"My belief is that if you were to scan someone's brain whilst they're reading aloud, there are probably very few parts of the brain that won't be working." [Dr David Fearnley]

Get Into Reading's innovative format makes it accessible for all, regardless of educational background.

\section{What to read}

On the topic of what to read, The Reading Cure presented a multifaceted discussion on whether or not it is essential to read literature. Won't reading anything - newspapers, magazines, 'trashy' novels - have the same effect on health? Well, no, it doesn't seem to be the case. There is something about reading great writing that engages people, that challenges people, and that enables them to focus: the difficulty leads to attentiveness, and brings a sense of real accomplishment. For some individuals, the Get Into Reading experience has been utterly transforming.

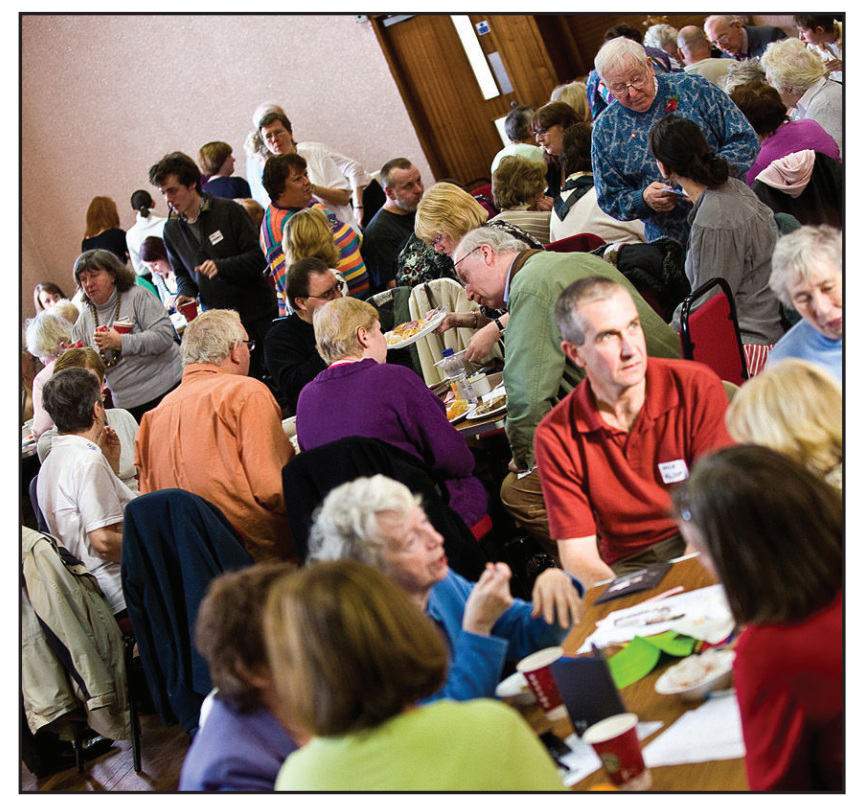

Figure 2 Photograph taken at the annual 'Get Into Reading' gettogether (photographs courtesy of Imran Ali) 
“For me it's been concentration. A lot of people who've got mental health problems can't concentrate, and you lose confidence in reading, the ability to read, and something like this is quite a gentle way back into that." [K, a Get Into Reading group member]

Group members have reported improvements in confidence, self-esteem, functional literacy, happiness levels, as well as fewer visits to the doctor. Although there has been some qualitative research undertaken, more evidence is required to support these findings. The Reader Organisation is currently working on several scientific studies and has recently been awarded money from Liverpool Primary Care Trust for an 18-month research project into reading and health.

Looking forward, The Reader Organisation aims to get more Get Into Reading groups available on prescription, as an alternative to drug-based medication. The project has been commended by Professor Louis Appleby, NHS Director for Mental Health:

"Get Into Reading is exactly the kind of work we at the Department of Health want to develop over the next 10 years - facing outward into the wider community and looking after mental health and well-being of the general population."

\section{Benefits of reading}

So, why should literature matter to health professionals? When we read, we go on a journey and this journey often teaches us new lessons, opens our eyes to new situations and helps us to get into the mind of another. There is undoubtedly a link between the complex actions of the brain whilst reading and the development of empathy within the reader. We cannot underestimate the power of health professionals' personal reading and the benefits that this has on their relations with patients and service users.

Medical professionals have been impressed by the very real difference reading literature makes to patients. Reading works like a therapy but unlike other therapies, Get Into Reading feels new, feels different.
Heavy workloads, masses of administration and a juggernaut of a system mean, with the best will in the world, that the human side of a job in health or social care can be hard to sustain. Many people working in these professions already know that reading helps them relax and unwind personally, but The Reader Organisation's unique model of shared reading at work goes further than that.

"Participants of GIR [Get Into Reading] groups show increased feelings of confidence, and benefits in personal functioning, such as concentration, memory, patience, reflection, calmness, ability to relax, self-awareness, and ability to cope with life. There are also benefits in social feeling, such as respect, tolerance, empathy, trust and belonging." [M Curran, Evaluative Report of the Get Into Reading Project, December 2007]

"I really enjoyed myself - it was the best bit of the day. I have a tsunami of work at the moment and taking time out improved my perspective immeasurably." [Bibby Line Group employee, Liverpool]

Shared reading - where the book is read aloud and discussed there on the spot - is also amazingly egalitarian and can help colleagues, as well as service users, see each other as fellow humans.

"In the reading group, the book is the expert." [Dr David Fearnley]

\section{The future}

Following the success of The Reading Cure, it is hoped that further seminars will be planned to reiterate the importance of this exciting area of study. In addition, The Reader Organisation is currently offering 'Read to Lead' training, for people across the country to learn how to deliver Get Into Reading in their own area. To find out more about these courses, and about The Reader Organisation's work, visit their website (www.thereader.org.uk)

Statements on funding and competing interests

Funding None identified.

Competing interests None identified.

\section{BOOK REVIEW}

Undertaking Sensitive Research in the Health and Social Sciences. Virginia Dickson-Swift, Erica L James, Pranee Liamputtong. Cambridge, UK: Cambridge University Press, 2008. ISBN113: 978-0-521-71823-3. Price: £27.99. Pages: 168 (paperback)

This is not a primer on "how to do research" on topics that may be sensitive, but how researchers might avoid the pitfalls inherent in these particular areas. Previously, sensitive topics have been defined as those where taboos operate; examples are death and dying, sexuality, violence, homelessness, HIV/AIDS or cancer. This book changes the focus from the topics to the researchers and participants, defining sensitive research as "research, which potentially poses a threat to those who are or have been involved in it". The authors report on the previous work done to safeguard the participants, but this book is to do with protecting the researchers. The authors quote others in stating that, for example, "in-depth interviewing necessitates establishing and maintaining good rapport with informants" and that this has to include emotional commitment from both parties.

The book contains examples of various types of qualitative research. Using a large number of quotations from researchers, the authors demonstrate how the boundaries often become blurred between being a researcher or a friend or confidant. They record how researchers feel when lured into revealing information about themselves in an interview. Health professionals will recognise the distancing technique to prevent emotional involvement with the participant, so that some objectivity can be retained. The book describes the difficulties of maintaining professional detachment in the face of disclosure and of emotional stories, some of which may resonate with episodes in the researchers' own lives.

Much of the book may be off-putting to potential qualitative researchers into sensitive topics, revealing to them previously unimagined risks and harms. Fortunately the final chapter contains many sensible recommendations. The authors describe developing a safety protocol for fieldwork, guidelines to protect those who transcribe harrowing interviews, support for the researchers, recommendations for research supervisors and many other preventative strategies.

Each chapter concludes with some tutoria material for readers to extend their knowledge and examine the practical applications of the research.

For health professionals, some of the language is obscure (for those not practised at reading social science articles). However, with persistence, the meaning can be obtained! This reader recognised the portrayal of the difficulties and dilemmas arising in the course of qualitative research into sensitive topics. Research supervisors should read it, as it is part of their job to prevent harm to the researchers under their supervision. It would also be useful reading for medical and nursing students (and the newly qualified) as they often find that setting boundaries between empathy and overinvolvement is difficult. And certainly, qualitative researchers should read it. Many who write articles on qualitative research have not considered the impact of their own identification with the emotional state of those they interview, either on themselves or on their research conclusions.

Reviewed by Gill Wakley, MD, FFSRH Advisory Editor, Journal of Family Planning and Reproductive Health Care 